\title{
aniki
}

Revista Portuguesa da Imagem em Movimento

Portuguese Journal of the Moving Image

\section{Editorial v5n2}

Os Editores

\section{O dossiê temático, a entrevista e os ensaios}

Encerramos o quinto ano de publicação da Aniki com um dossiê temático intitulado "O cinema brasileiro na era neoliberal", que mapeia as formas como o cinema brasileiro tem respondido ao projeto neoliberal e em que termos tem participado e resistido a esse mesmo projeto. O dossiê foi editado por Lúcia Nagib (Universidade de Reading, Reino Unido), Ramayana Lira de Sousa (Universidade do Sul de Santa Catarina, Brasil) e Alessandra Brandão Soares (Universidade Federal de Santa Catarina, Brasil), que o apresentam mais detalhadamente na introdução. Todos os textos do dossiê foram submetidos a um processo de revisão cega por pares.

Este novo número da Aniki conta com duas entrevistas. A primeira surge no âmbito do habitual dossier temático, desta feita dedicado ao cinema brasileiro na era neoliberal. Lúcia Nagib, uma das editoras convidadas, juntamente com Samuel Paiva, falaram com Tata Amaral, influente realizadora da chamada Retomada do Cinema Brasileiro. Esta é uma conversa que, partindo de algumas das suas obras mais importantes, como são o caso de Um Céu de Estrelas (1997) ou Antônia (2009), se foca sobretudo no uso de outras formas artísticas (pintura, música, teatro, fotografia) no interior do seu cinema como passagem para a realidade sociopolítica do Brasil. A segunda entrevistada é Catherine Grant, conhecida académica britânica e keynote speaker da edição de 2017 dos encontros da AIM (Associação de Investigadores da Imagem em Movimento). Sérgio Dias Branco, Professor de Estudos Fílmicos da Universidade de Coimbra, conduz esta preciosa entrevista que toca múltiplos aspetos ligados às transformações políticas e tecnologias da investigação e do ensino, em particular das humanidades, à importância e potencialidades pedagógicas do formato ensaio audiovisual, assim como as nuances e evoluções da sua carreira académica, que atravessa não só diversos campos de investigação, como também vários projetos ligados a diversas plataformas de publicação sobretudo em ambiente digital.

A secção "Ensaios" recebe permanentemente submissões fora do tema do dossiê. Em "Tempo, Trânsito, Subjetividade em En Construcción (José Luis Guerín, 2000) e El Cielo Gira (Mercedes Álvarez, 2004)," Rafael Tassi Teixeira analisa estes dois documentários espanhóis, realizados na primeira metade dos anos 2000 no âmbito do Master de Documental de Creacíon, criado em 
1998 na Universidad Pompeu Fabra (Barcelona), que rapidamente se tornaram paradigmáticos do questionamento da metáfora fílmicorealista na mais recente história do cinema documentário. A análise fílmica destes dois filmes leva o autor a incidir em temas bastante atuais tais como memória e subjetividade, multiculturalismo e transformação urbana, construção e desaparição, encontrando uma linha de pensamento comum na ligação arqueológica primária que enceta entre o tempo e as memórias pessoais e coletivas com os lugares habitados.

"Ensaio sobre A-Encenação no Filme Documentário" é, tal como o próprio título anuncia, um ensaio no qual o autor, Fernão Pessoa Ramos, reflete filosoficamente sobre as modalidades de encenação (mise-en-scène) do cinema documentário. De modo a aprofundar a compreensão das práticas da encenação documentária contemporânea, o autor introduz o conceito de "a-encenação" de forma a passar em revista processos afetivos e hápticos que estão presentes nas configurações sensoriais dos corpos, visíveis e audíveis em realizadores tão diversos como Lucien Casting-Taylor e Chantal Akerman, passando por Pedro Costa, Harun Farocki, Cao Guimarães, Eduardo Coutinho, entre muitos outros, nos quais as diversas modalidades de a-encenação são mais evidentes.

A partir da análise fílmica de Adeus, Dragon Inn (2003), de Tsai Ming-liang, Marcos Aurélio Felipe apresenta-nos uma reflexão ontológica sobre as cartografias do cinema, no presente e no passado, buscando compreender a incomunicabilidade e a sexualidade na fundação das subjetividades contemporâneas. Em "Problemáticas do Contemporâneo em Tsai Ming-liang: Memória, Distanciamentos e Sexualidade", o autor enceta um diálogo teórico entre Ming-liang e outros cineastas asiáticos contemporâneos, tais como Jia Zhang-ke, Apichatpong Weerasethakul, Hou Hsiao-hsien e Wong Kar-wai, com o intuito de procurar respostas para a separação afetiva, para a ausência clara de um relacionamento intersubjetivo das suas personagens, que, no limite, vem questionar a própria ontologia do cinema marcada, justamente, por essa partilha afetiva.

Encerrando a secção, Horacio Muñoz Fernández, inspirado pela relativamente recente importância dada ao debate crítico das séries televisivas, interroga a necessidade da sua legitimação cultural. $\mathrm{O}$ autor percorre alguns dos principais argumentos a favor da valorização e da avaliação estética das séries televisivas centrando o seu ponto de vista na questão Kantiana do juízo de gosto. O autor de "La (des)legitimación cultural de las series de televisión" relaciona o juízo de gosto elaborado pelas cadeias televisivas com práticas de consumo, classes sociais, minorias e género, de modo a procurar o(s) novo(s) elemento(s) que poderíamos encontrar numa série televisiva mas que não encontraríamos na literatura ou no cinema, artes já legitimadas e com as quais se faz, frequentemente, uma 
analogia no sentido de encontrar critérios de qualidade artística para as séries televisivas.

\section{As recensões de livros e conferências}

Esta edição inclui quatro recensões e um relatório relativo a uma conferência. Abre com a recensão, por Fátima Chinita, de Screening Statues: Sculpture and Cinema, de Steven Jacobs, Susan Felleman, Vito Adriaensens e Lisa Colpaert. Não obstante tratar-se de uma obra, sobre a relações entre escultura e cinema, escrita por autores em parceria, Chinita considera que o resultado é perfeitamente articulado, além ter uma qualidade científica uniforme, tornando este livro um contributo fundamental, e que vem suprir um vazio, para os investigadores na área do cinema e outras formas de expressão artística.

Segue-se, por Ana Isabel Soares, a recensão a Os pobres no cinema de Manoel de Oliveira, coordenada por Renata Soares Junqueira e que reúne ensaios de alguns dos principais investigadores que, de um e outro lado do Atlântico, têm estudado a obra oliveiriana. Assumindo o estudo de um eixo destacado da cinematografia de Oliveira, toma quer o comparatismo quer a interdisciplinaridade como orientadores dos vários ensaios. Se um objectivo assumido era o de iluminar a dimensão política do cinema do realizador do Porto, a autora da recensão afirma que uma das suas consequências mais interessantes é "a clareza como surgem imbricadas a dimensão política e a religiosa".

Cinema El Dorado - Cinema e Modernidade, de Fernando Guerreiro, foi publicado em 2015 e lido por Elisabete Marques em 2018. A autora considera que o livro teve escassa receção crítica, mesmo atendendo às suas características e ao programa ambicioso, "plasmado na estrutura e no arcabouço conceptual e bibliográfico a que recorre". Marques considera que se trata de uma obra que, sendo extensa, complexa e por vezes mesmo labiríntica, não é de leitura difícil, exigindo um leitor ativo e criador, e tão pouco é fácil de sintetizar. Trata-se de uma obra "rizomática”, “compósita”, em que a articulação dos argumentos é frequentemente opaca, mas que se afirma como incontornável, vindo enriquecer a bibliografia embora não apresente uma, facto a lamentar - dos estudos de cinema em Portugal.

Manuela Penafria assina a recensão a Viagens, olhares $e$ imagens: Portugal 1910-1980 que, com coordenação de Sofia Sampaio, reúne entrevistas feitas sobretudo a profissionais de cinema que dirigiram ou participaram na realização de filmes turísticos, além de vários textos de investigadores do projeto que apresentaram, na Cinemateca Portuguesa, várias sessões de filmes organizadas no âmbito de uma investigação científica desenvolvida em parceria com esta instituição e apoio da Fundação para a Ciência 
e Tecnologia. O livro, que integra ainda os textos dos dois consultores, Tobby Miller e Tiago Baptista, documenta, segundo Penafria, "uma boa ideia de investigação".

Finalmente, Fátima Chinita relata os trabalhos durante a IntermIdia Conference II: The Moving Form of Film: Exploring Intermediality as a Historiographic Method, que decorreu na Universidade de Reading de 6 a 8 de Novembro de 2017. A autora refere que não é demais sublinhar a originalidade deste projeto dado que a intermedialidade nunca antes foi proposta e usada como método historiográfico, sintetizando como foi estruturada a conferência e notas principais propostas pelos keynote speachers Luciana Araújo, Ismail Xavier, Robert Stam e, não obstante a sua ausência física, por Alain Badiou.

\section{As exposições e festivais}

A secção "Exposições e festivais" conta, neste número, com duas contribuições. A primeira, assinada pelo duo de cineastas Silvia Maglioni e Graeme Thomson, assume a forma de um diálogo entre ambos, a propósito da retrospectiva Shinsuke Ogawa \& Ogawa Pro que decorreu em março-abril deste ano no Cinéma du Réel e no Jeu de Paume. Maglioni e Thomson evocam neste texto inédito o impacto que a descoberta da filmografia do cineasta japonês e do seu colectivo teve sobre eles, questionando alternativamente o que significa pensar hoje o cinema como uma forma de resistência e/ou de vida. O diálogo dos dois artistas constitui um formidável tributo ao trabalho documental, infelizmente ainda pouco conhecido, de Shinsuke Ogawa (1936-1992). Figura central do cinema japonês, Ogawa cria em finais dos anos 60 um colectivo que documentará, numa primeira fase, as violentas revoltas estudantis que agitam então o Japão e, entre 1968 e 1977, o combate dos estudantes e dos camponeses da região de Sanrizuka contra a construção do aeroporto internacional de Narita. Em finais dos anos 70, o colectivo instala-se na pequena aldeia de Magino, na região de Yamagata, vivendo em comunidade, trabalhando durante longos anos nos arrozais e realizando uma série de longas-metragens excepcionais sobre a vida na aldeia, e a história moderna e antiga do Japão. Se o texto de Maglioni e Thomson constitui, antes de mais, uma demonstração dos poderes do cinema, o mesmo vem também homenagear o excelente trabalho de "passador" realizado pelo programador Ricardo Matos Cabo. O impacto da retrospectiva, à qual a imprensa esteve muito atenta, não deixará certamente de se fazer sentir na esfera francófona.

O segundo texto da secção, assinado precisamente por Ricardo Matos Cabo, concentra-se, por sua vez, na exposição em torno do cineasta e historiador alemão Günter Peter Straschek (1942-2009), "Emigration - Film - Politik", organizada no Museu 
Ludwig, em Colónia. Tal como Ogawa, Straschek é uma figura mítica, mas ainda pouco conhecida, do cinema documental. Colega de Hartmut Bitomsky, Harun Farocki e Helke Sander na Academia alemã de Televisão e Cinema, da qual foi expulso por razões políticas, Straschek é mais conhecido por ter realizado uma série documental de cinco horas sobre a emigração e o exílio de mais de 2000 cineastas e outros trabalhadores da indústria cinematográfica durante o período nazi. No seu texto, Matos Cabo evoca detalhadamente este e outros trabalhos apresentados em Colónia, entre os quais se contam dois filmes até hoje considerados perdidos: Ein Western für den SDS (1967/68, filme que lhe valeu a expulsão da academia) e Zum Begriff des „kritischen Kommunismus“ bei Antonio Labriola (1970). 